\title{
NEUMONÍA ATÍPICA EN UN PACIENTE ADULTO JOVEN INMUNODEPRIMIDO
}

\author{
ATYPICAL PNEUMONIA IN A YOUNG ADULT PATIENT IMMUNOSUPPRESSED \\ Díaz Vasti a Cari Flor a , Poma Humberto ${ }^{\text {b }}$
}

\begin{abstract}
RESUMEN
Introducción: Las neumonías atípicas son infecciones oportunistas que ponen en riesgo la vida del paciente inmunocomprometido. Siendo el objetivo de este estudio revisar los factores predisponentes, características clínicas y respuesta terapéutica en pacientes $\mathrm{VIH}+$.
\end{abstract}

Caso Clínico: Paciente varón de 31 años de edad de Lima, soltero, refiere haber sido consumidor de cocaína por 5 años (1999-2003), así mismo menciona haber tenido 5 parejas sexuales. Presento cuadro clínico pulmonar hace 2 meses. Se le diagnostica erróneamente un cuadro de Neumonía Adquirida en la Comunidad. Así mismo, durante su hospitalización se confirma el diagnostico $\mathrm{VIH}$; su cuadro clínico se profundiza y no responde al tratamiento dado. Se plantea como diagnósticos diferenciales la tuberculosis y neumocistis.

Resultados: Se realizó los exámenes correspondientes de laboratorio destacando leucocitosis (22 340 por $\mathrm{mm} 3$ ), linfocitosis de un $10 \%$, PCR de 8 , $\mathrm{LDH}$ de $1034 \mathrm{UI} / \mathrm{Ml}$, VSG de $95 \mathrm{~mm} / \mathrm{h}$ y BK-. Al examen radiológico se encontró un patrón de vidrio esmerilado que nos indica infiltración Interlobulillar y alveolar. Se confirma diagnóstico de Pneumocistis jirovecii y se evidencio respuesta terapéutica positiva al tratamiento con Cotrimoxazol (Trimetropín $15-20 \mathrm{mg} / \mathrm{kg} /$ día y Sulfametoxazol 75-10mg/kg/día).

Conclusiones: Los factores predisponentes: La promiscuidad (5 parejas sexuales) y contacto con grupos de riesgo (trabajadoras sexuales), adicciones y hábitos (consumo de Cocaína). La forma clínica de presentación: cuadro clínico, radiografía y TAC de tórax, estudios de laboratorio y respuesta terapéutica confirmatoria en este tipo de pacientes inmunocomprometidos, constituyendo actualmente un marcador de $\mathrm{VIH}+$.

PALABRAS CLAVE: Neumonias Adquiridas en la Comunidad (NAC); Pneumocisty jirovecii; paciente inmundeprimido.

\begin{abstract}
Introduction: Atypical pneumonias are opportunistic infections that threaten the life of the immunocompromised patient. As the objective of this study review the predisposing factors, clinical features and therapeutic response in HIV + patients.
\end{abstract}

Clinical case: Male patient, 31 years old from Lima, single, concerns have been consuming cocaine for 5 years (1999-2003), also mentions having had 5 sexual partners. Pulmonary clinical picture presented two months ago. misdiagnosed him a picture of community-acquired pneumonia. Also during hospitalization HIV diagnosis is confirmed; It deepens its clinical picture and does not respond to treatment given. Differential diagnosis is presented as tuberculosis and pneumocystis.

Results: the corresponding laboratory tests highlighting leukocytosis (22 340 per mm3), lymphocytosis of 10\% PCR 8, LDH 1034 IU / Ml, ESR 95 mm / h and BK-was performed. The radiological examination frosted glass pattern which indicates interlobular and alveolar infiltration was found. Pneumocystis jirovecii diagnosis is confirmed and positive therapeutic response to treatment with cotrimoxazole (trimethoprim 15-20 mg / kg / day and sulfamethoxazole $75-10 \mathrm{mg} / \mathrm{kg} /$ day) was effective.

Conclusions: The predisposing factors: Promiscuity (5 sexual partners) and contact with risk groups (sex workers), addictions and habits (cocaine). The clinical presentation: clinical, radiographic and chest CT scan, laboratory studies and confirmatory therapeutic response in immunocompromised patients such now constituting a marker of HIV +.

KEYWORDS: Community acquired pneumonias (CAP); Pneumocisty jirovecii; inmundeprimido patient.
aEAP. Medicina Humana, Facultad de Ciencias de la Salud, Universidad Peruana Unión, SOCEM - UPeU.

bServicio de Medicina Interna - Infectología, Hospital Nacional Guillermo Almenara Irigoyen.

\section{Correspondencia: \\ Vasti Evelin Diaz Quiquia Dirección: \\ Escuela de Medicina, UPEU Carretera Central 19.5, Ñaña, Lurigancho Teléfono: 6186300 Correo electrónico: vasty.7.jerusalen@gmail.com}




\section{INTRODUCCIÓN}

Las Neumonías Adquiridas en la Comunidad (NAC) o extrahospitalarias, consiste en una inflamación del parénquima pulmonar por causa infecciosa, viene hacer una de las principales causas de mortalidad y principal causa de consulta ambulatoria, en las poblaciones desarrolladas y en vías de desarrollo', presentando una incidencia de 1,62 (8 a 15 casos aproximadamente) por 1000 habitantes, con mayor frecuencia en el invierno, en infantes y adultos mayores de 65 años y varones ${ }^{2,3}$. Otro estudio publicado en Chile dice que la NAC es una enfermedad infecciosa respiratoria aguda que tiene una incidencia que oscila entre 3 y 8 casos por 1.000 habitantes por año. Esta incidencia aumenta con la edad y las comorbilidades, siendo la mortalidad global por causa del NAC alrededor del 10\%4.

Se debe tener presente que la neumonía puede ser de presentación típica o bacteriana; atípica, no bacteriana, ni vírica y no clasificable. Además, la neumonía atípica no se presenta con una sintomatología común de las neumonías (No escalofríos, tos seca poco productiva) 5 .

En el Perú, la NAC es la primera causa de mortalidad, siendo el Streptococcus pneumonia, agente causante de $36-49 \%$ de los casos, asociaciones polimicrobianas un $19 \%$ y la flora anaeróbica y Haemophilus influenzae un $11 \%$, las infecciones virales puede causar una proporción desde $2.2-23 \%$ de casos como neumonías típicas y los considerados como microorganismos "atípicos" a la Legionella y Mycoplasma ${ }^{6}$.

Entre los factores predisponentes de desarrollo de NAC, encontraremos que las edades extremas son las más vulnerables (niños y el adulto mayor), varones, diversos grupos étnicos, los estilos de vida, como el consumo excesivo de alcohol, uno de los más importantes hábitos; fumador, tanto pasivo como activo, uso de medicamentos y condiciones de comorbilidad como las enfermedades cardiorrespiratorias crónicas, insuficiencia renal crónica, diabetes mellitus, enfermedades neoplásicas, VIH, enfermedades hepáticas. Enfermedad neurológica crónica, etc ${ }^{7,8}$. Uno de los factores de riesgo más importantes es la infección con $\mathrm{VIH}$ y esto con lleva a la presentación de mayor probabilidad de desarrollo de complicaciones por ser pacientes inmunocomprometidos ${ }^{7}$. Siendo el objetivo de nuestro estudio poder lograr revisar los factores predisponentes, características clínicas y respuesta terapéutica en pacientes con diagnóstico de $\mathrm{VIH}+$.

\section{PRESENTACIÓN DEL CASO}

Paciente varón de 31 años de edad, residente en Lima, soltero, con secundaria completa, trabaja como repartidor de gaseosas, refiere antecedentes de tabaquismo con consumo de 5 cigarrillos al día, alcohol los fines de semana, consumo de cocaína por un periodo de 5 años (1999-2003). Además, manifiesta haber iniciado su vida sexual a los 14 años y haber mantenido relaciones sexuales con trabajadoras sexuales (prostitutas). Apendicectomía a los 36 años sin complicaciones, sin antecedentes heredofamiliares de importancia.

El padecimiento actual se inicia 2 meses previos a su ingreso, en forma insidiosa y curso progresivo, refiere apreciar pérdida de peso progresivo, un mes antes a su ingreso se agrega disnea al esfuerzo, progresa a mayor dificultad respiratoria y 3 semanas antes de su ingreso se inicia tos seca no productiva, sudoración nocturna y síntoma de alza térmica (SAT). Es ingresado al HDU el 8 de abril, con mal estado general, caquéctico y dificultad respiratoria, donde lo catalogan como una NAC, y se inicia con la administración de ceftriaxona. Por los antecedentes manifestados se realiza un examen, el 28 de abril, para descartar VIH el cual es positivo. Es trasferido al Hospital Nacional Guillermo Almenara Irigoyen. Donde al Examen general tenemos una temperatura de $36.8^{\circ} \mathrm{C}$, Frecuencia cardiaca de $80 \mathrm{lpm}$, frecuencia respiratoria de 22 rpm, Presión arterial de 100/60 $\mathrm{mmHg}$ y peso de $38 \mathrm{Kg}$. En aparente mal estado general, aparente regular estado hídrico, Aparente mal estado nutricional y caquéctico, En la piel se evidenciaba una ulcera superficial de 1,5 x 1,5 cm en región lumbar, sin secreciones y un cicatriz de aproximadamente $6 \mathrm{~cm}$ en hemicara derecha; el tejido celular subcutáneo está muy disminuido y no presenta edemas y en los dedos de los pies se encuentran onicomicosis. Se palpa adenopatías de $0.5 \mathrm{~cm}$ en la región cervical, la cual es móvil y no dolorosa. Su aparato locomotor esta conservado. La exploración cardiaca y pulmonar no evidenció datos relevantes. El abdomen estaba escavado, RHA presentes, blando, depresible, no visceromegalia, no masas, no doloroso a la palpación superficial ni profunda. En el Aparato Genitourinario se encuentra negativo a puño percusión lumbar (PPL) y punto retroureteral (PRU). No se observan lesiones en genitales, ni en la región peri anal.

El laboratorio de ingreso mostró hematocrito $40 \%$, hemoglobina $12.7 \mathrm{mg} / \mathrm{dl}$, leucocitos de $22340 / \mathrm{mm} 3$, glu $\neg$ cemia $102 \mathrm{mg} / \mathrm{dl}$, creatinina $0.89 \mathrm{mg} / \mathrm{dl}$, TGO 44 IU/I, TGP 15 IU/I, LDH 1034 IU/I, VSG 95 mm en la primer hora, proteínas totales de $60 \mathrm{~g} / \mathrm{dl}$, albúmina $2.2 \mathrm{~g} /$ dl, PCR=7.4 (Tabla 1 y2). Orina normal. Además los Bk fueron negativos en varias oportunidades. 
Tabla 1. Resultados relevantes de las pruebas de laboratorio.

\begin{tabular}{|c|c|c|c|c|c|c|}
\hline Fecha & $08 / 04$ & $18 / 04$ & $21 / 04$ & $24 / 04$ & $30 / 04$ & $05 / 05$ \\
\hline Creatinina & 0.89 & - & - & - & 0.40 & - \\
\hline Glucosa & 102 & - & - & - & 113 & - \\
\hline TGO & 44 & 49 & 41 & 39 & 467 & 79 \\
\hline TGP & 15 & 26 & 20 & 18 & 201 & 124 \\
\hline GGTP & - & - & - & - & 494 & 640 \\
\hline Proteínas & 60 & 63 & - & - & 55 & 56 \\
\hline Albumina & 2.2 & 2.1 & - & - & 1.6 & 1.7 \\
\hline FA & - & - & - & - & 466 & 624 \\
\hline
\end{tabular}

Nota: TGO=Transaminasa glutámico oxalacética; TGP=Transaminasa glutámico pirúvica; VSG=Velocidad de Sedimentación globular; GGTP= Gamma glutamil transpeptidasa; FA= Fosfatasa Alcalina.

Tabla 2. Resultados de laboratorio relacionados al hemograma completo.

\begin{tabular}{lccccccc}
\hline Fecha & $\mathbf{0 8 / 0 4}$ & $\mathbf{1 4 / 0 4}$ & $\mathbf{1 8 / 0 4}$ & $\mathbf{2 1 / 0 4}$ & $\mathbf{2 4 / 0 4}$ & $\mathbf{3 0 / 0 4}$ & $\mathbf{0 5 / 0 5}$ \\
\hline Leucocitos & 22.340 & 12.710 & 17.420 & 7.060 & 10.360 & 5.70 & 4.53 \\
\hline Linfocitos & - & $10 \%$ & $33 \%$ & $15 \%$ & $5 \%$ & - & - \\
\hline Hto & 40 & 36 & 42 & 38 & 36 & 39 & 34 \\
\hline Hb & 12.7 & 11.4 & 12 & 11 & & 12.2 & 10.5 \\
\hline Plaquetas & - & 362 & 435 & 448 & 427 & - & 586 \\
\hline DHL & 1034 & - & - & 1093 & 924 & - & - \\
\hline PCR & 7,4 & 8 & - & 8 & - & - \\
\hline VSG & 95 & 90 & 80 & - & 100 & - \\
\hline
\end{tabular}

Nota: $\mathrm{Hto}=$ Hematocrito; $\mathrm{Hb}=$ Hemoglobina; $\mathrm{DHL}=$ Lactato deshidrogenasa; $\mathrm{PCR}=$ Proteína $\mathrm{C}$ reactiva VSG=Velocidad de Sedimentación globular.

Los resultados del Análisis de Gases Arteriales (AGA) a su ingreso con un $\mathrm{FiO}=50 \%$, por lo que se le encontró con bolsa de oxígeno, $\mathrm{pH}=7.4 ; \mathrm{pCO} 2=45.3 \mathrm{mmHg} ; \mathrm{pO}=97.3 \mathrm{mmHg} ; \mathrm{Sat}=95.8 \% ; \mathrm{PaFi}=194 \mathrm{mmHg}$ y HCO3= 28 (Tabla 3).

Tabla 3. Resultados de la Gasometría Arterial en el transcurso de la hospitalización.

\begin{tabular}{lcccc}
\hline Fecha & $\mathbf{0 9 / 0 4}$ & $\mathbf{0 2 / 0 5}$ & $\mathbf{0 3 / 0 5}$ & $\mathbf{0 5 / 0 5}$ \\
\hline Fio & $50 \%$ & $50 \%$ & $50 \%$ & $50 \%$ \\
\hline Ph & 7.4 & 7.4 & 7.4 & 7.4 \\
\hline pCO2 & 45.3 & 40 & 40 & 43.6 \\
\hline PO2 & 97.1 & 145 & 158 & 95.2 \\
\hline SAT & $95.8 \%$ & $97.8 \%$ & $98.8 \%$ & $97 \%$ \\
\hline PaFi & 194 & 290 & 148.6 & 190 \\
\hline HCO3 & 28 & 27 & 27 & 28.6 \\
\hline
\end{tabular}

Nota: $\mathrm{FiO}=$ Fracción de inspiración de oxígeno; $\mathrm{pCO} 2=$ Presión parcial de $\mathrm{CO} 2 ; \mathrm{pO} 2=$ Presión parcial de $\mathrm{O} 2 ; \mathrm{SAT}=$ Saturación de oxígeno; PaFi=Relación entre la Presión parcial de $\mathrm{O} 2$ y la Fracción inspirada de $\mathrm{O} 2: \mathrm{HCO} 3=$ Bicarbonato. 
La tomografía de tórax mostró pequeñas imágenes nodulares bilaterales evidenció opacidades de aspecto nodular con halo en vidrio esmerilado circundante en ambos pulmones (Figura 1A), que nos indica un incremento del infiltrado interlobulillar y alveolar. Todo nos da positivo para Pneumocisti jirovecii. Además se evidencia un broncograma aéreo, destrucción del parénquima alveolar y presencia de imágenes quísticas (Figura 2). Por el diagnóstico dado, se inicia tratamiento con Cotrimoxazol (Trimetropín 15-20 mg/kg/dia y Sulfametoxazol 75-10mg/kg/dia), imipenem 500 mg, vamcomicina $1 \mathrm{gr}$.
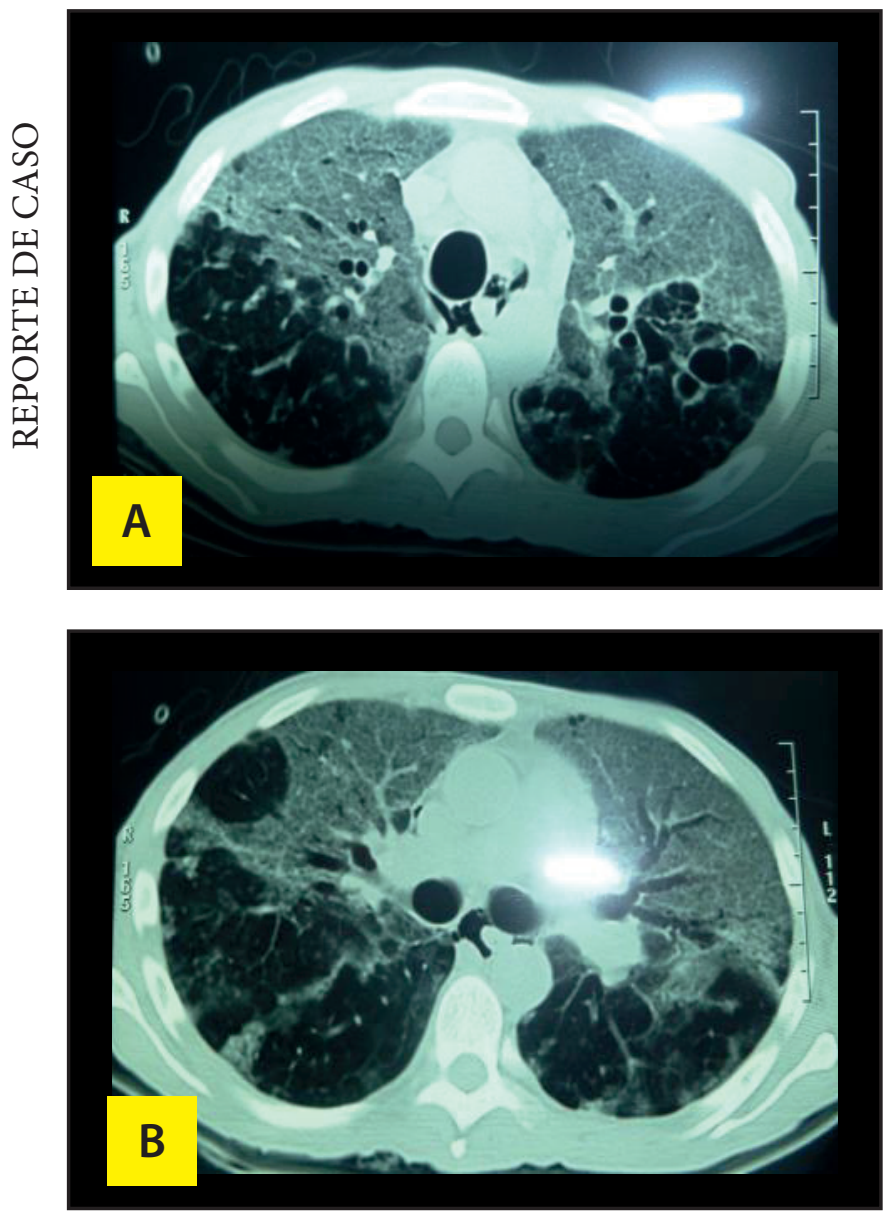

Figura 1. Tomografía con contraste del Tórax. A. Evidencia patrón de vidrio esmerilado. B. Broncograma aéreo, destrucción del parénquima e imágenes quísticas.

\section{DISCUSIÓN. (CONFRONTACIÓN BI- BLIOGRÁFICA CON LOS RESULTA- DOS ALCANZADOS)}

Se presentan muchos riesgos diagnósticos con los pacientes inmunodeprimidos, entre una de esas complicaciones están las neumonías atípicas Según Gassiot y col. las neumonías por Pneumocistis carinii y bacterianas, así como la tuberculosis, son las neumopatías más frecuentes en el mundo actual ${ }^{7}$ Por otro lado en 1981, el centro de control de enfermedades de los Es- tados Unidos dio a conocer nuevos casos de neumonía por Pneumocistis carinii, y es así como se conoce la existencia del $\mathrm{VIH}^{8}$, seguido por otros síntomas como diarrea y pérdida de peso. Así mismo, Nieto publica que los pacientes que se encuentran en una Fase tardía del $\mathrm{VIH}$, presentan un alto riesgo de desarrollar infecciones oportunistas y tumores como Tuberculosis, Neumonía por Pneumocistis Carinii, linfoma no Hodgkin, sarcoma de Kaposi, asimismo pueden presentar afecciones neurológicas como encefalopatía $\mathrm{VIH}^{8}$.

Como se mencionó la Pneumocisti jirovecii afecta con mayor frecuencia a los pacientes $\mathrm{VIH}(+)$, con presentación insidiosa y manifestaciones clínicas de mal estado general, fiebre, tos- mayormente no productiva- y disnea progresiva, dolor retroesternal. Al examen físico, en ocasiones se manifiesta estertores húmedos y raramente sibilancias, asociado a signos de toxinfección y taquipnea ${ }^{7,9}$.

Entre las manifestaciones radiológicas, comúnmente se hallara infiltrados alveolares difusos e intersticiales, a veces asimétricos e irregulares. En los casos de profilaxis previa, hay predominio de las lesiones hacia los lóbulos superiores, se detectan quistes subpleurales y neumotórax. Son raros el derrame, las lesiones endobronquiales y las adenopatías intratorácicas. El estudio radiológico en nuestro paciente mostró un patrón en vidrio esmerilado, esto se correlaciona con estudios en los que se encontraron una incidencia de aproximadamente $35 \%$ de este tipo de compromiso ${ }^{10}$.Además otro estudio manifiesta que los pacientes que fueron ingresados para estudios complementarios, especialmente de tipo radiológico, revelaron imágenes de infiltrados pulmonares parahiliares difusos, típicas de infección por pneumocistis jirovecii, aproximadamente en el 90 $\%$ de los casos, en pacientes inmunodeprimidos por $\mathrm{HIV}^{11}$.

Conjuntamente, se debe tener muy en cuenta que se eleva la enzima LDH en más del $90 \%$ de los casos de Pneumocisti jirovecii, pero es poco específica, ya que esto puede ocurrir también en la tuberculosis y el linfoma. El método microscópico, con uso del esputo y método de tinción, no es muy sensible a la P.jirovecii, por esto del uso de PCR, ya que revela la colonización del pulmón por le P. jirovecii, trabajando por el medio del ADN, a pesar de ello puede estar relacionado a otros factores. Los niveles altos de leucocitos y el VSG, nos da un panorama de existencia de infección en el paciente ${ }^{12}$.

Se debe de considerar que la Pneumocsytis Jirovecci se allá con mayor frecuencia, variante de un país a otro y oscila entre 30 y $43 \%$ de las infecciones oportunistas y además presenta una incidencia mayor en pacientes con edad de 31 a 40 años como es el caso de nuestro paciente y ocupando un segundo pico de 61 a 70 años. Otro punto resaltante entre los antecedentes, fue el tener Infección por VIH ${ }^{13,14}$ (Tabla 4). 
Tabla 4. Características epidemiológicas de pacientes con neumonía con P. Jirovecii.

\begin{tabular}{|c|c|c|c|}
\hline & $\begin{array}{c}\text { PACIENTES (40) } \\
\text { PRESENCIA DE P. JIROVECII }\end{array}$ & $N^{\circ} 14 / 40$ & (35) \\
\hline & \multicolumn{3}{|l|}{ Edad (años) Rango (15- 68 años). } \\
\hline & $10-20$ & 3 & 21.4 \\
\hline & $21-30$ & 2 & 14.3 \\
\hline & $31-40$ & 3 & 21.4 \\
\hline & $41-50$ & 1 & 7.1 \\
\hline & $51-60$ & 2 & 14.3 \\
\hline & $61-70$ & 3 & 21.4 \\
\hline & \multicolumn{3}{|l|}{ SEXO } \\
\hline & Femenino & 7 & $(50.0)$ \\
\hline & Masculino & 7 & $(50.0)$ \\
\hline & \multicolumn{3}{|l|}{ ANTECEDENTES } \\
\hline & Infección por el VIH & 6 & 42.8 \\
\hline & Insuficiencia renal crónica & 2 & 14.2 \\
\hline & Trasplante renal & 1 & 7.1 \\
\hline & Neumopatía crónica & 5 & 35.7 \\
\hline
\end{tabular}

Cermeño y col. dio a conocer una lista de las principales manifestaciones clínicas (Tabla 5) observadas en los pacientes inmunocomprometidos con pneumocistis, en las cuales la tos y expectoración, la fiebre y la pérdida de peso, relacionadas a las encontradas en el caso.

Tabla 5. Características epidemiológicas de pacientes con neumonía con P. Jirovecii.

\begin{tabular}{lc}
\hline \multicolumn{1}{|c}{ SIGNOS Y SÍNTOMAS } & PORCENTAJE (\%) \\
\hline Tos y expectoración & 85.7 \\
\hline Fiebre & 71.4 \\
Pérdida de peso & 50.0 \\
Insuficiencia respiratoria & 28.5 \\
Disnea & 28.5 \\
Patrón radiológico: infiltrado bilateral difuso & 28.5 \\
Dolor torácico & 21.4 \\
\hline
\end{tabular}

Entre los factores de riesgo que se encontraron en este paciente y que al compararse con un estudio observacional en España y publicado el 2012 por Solano y col., se hallaron un mismo patrón para el diagnóstico de Pneumocystis jirovecii, los cuales fueron: la edad ( $41,3 \pm 12$ años), el sexo (63,9\% eran hombres) y antecedente de VIH $(86,1 \%)^{15}$. Otro factor predisponente que tuvo este paciente para tener la enfermedad, fue el abuso de drogas intravenosas, como lo mencionan diversos artículos publicados dese los inicios del SIDA, hasta los publicados recientemente ${ }^{16,17}$. Al diagnosticarse P. Jirovecii, el paciente recibió el tratamiento adecuado, siendo la primera línea de profilaxis el cotrimoxazol, se recomienda la asociación con corticoides sistémicos, para procesos de intolerancia, es caso de presentarse ${ }^{9}$. 


\section{CONCLUSIÓN}

Mediante este caso clínico, se puso en manifestó una forma de diferenciación entre un cuadro común de NAC, principalmente entre la neumonía típica y típica, con las diferentes manifestaciones. Para el desarrollo de este caso clínico se deben tener en cuenta diferentes factores predisponentes como la promiscuidad (5 parejas sexuales), adicciones y hábitos (consumo de Cocaína); la forma clínica de presentación con el cuadro clínico de tos no productiva necesariamente, disnea, fiebre. Además a las manifestaciones de tomografía de tórax, estudios de laboratorio confirmatorios y la respuesta terapéutica adecuada en pacientes inmunocomprometidos, pueden llegar a determinar neumonías atípicas como la neumonía por Pneumocistis carinii o ahora conocido como Pneumocistis Jirovecii, siendo este un marcador de VIH. En otras palabras, es un

\section{REFERENCIAS BIBLIOGRÁFICAS}

marcador muy importante para el desarrollo de la P. jirovecii y mayor probabilidad de desarrollo de la patología en pacientes inmunocomprometidos.

\section{AGRADECIMIENTOS}

Al Prof. Dr. Jhony A. De La Cruz. Jefe de docencia e investigación de la clínica Good Hope, por brindar su tiempo y paciencia para el asesoramiento de la relación del caso clínico.

Fuente de financiamiento: Autofinanciado.

Conflicto de interés: Los autores declaran no tener conflictos de interés en la publicación de este artículo.

Recibido: 07/03/2016

Aprobado: 26/04/2016
1. Fernando Saldías $P$, José Miguel Mardónez U, Miguel Marchesse $R$ Paola Viviani G, Gonzalo Farías G4, Alejandro Díaz F1. Neumonía adquirida en la comunidad en el adulto hospitalizado. Cuadro clínico y factores pronósticos. Rev Méd Chile 2002; 130: 1373-1382

2. Martín J.J., Padilla A, Acosta. Neumonías Adquiridas en la comunidad, consultado el 4 de Junio del 2014. Neumosur.

3. Ballestores CG, De Jesus F, Espinoza T, Lopez I, Sanche HE. Neumonia adquirida en al comunidad. Archivos de Medicina de Urgencia de México. Vol.2 Num 1 Enero-Abril 2010 pag. 35.39, 19 de marzo del 2010

4. Antoni Torres. Guía multidisciplinar para la valoración pronóstica, diagnóstico y tratamiento de la neumonía adquirida en la comunidad Medicina Clínica. Volume 140, Issue 5 , 2 de marzo de 2013, Pages 223. e1-223.e19

5. Méndez A, García MJ. Baquero F, Del castillo F. Neumonía adquirida en la comunidad. Protocolos diagnóstico-teraputico de la AEP: Infectología pediátrica. AEP. Consultado el 08 de junio del 2014

6. Boletín epidemiológico(Lima). MINSA. Dir gen de epid, red Nac de Epid. Numero 35, Vol. 21 2012. Med. Epid. Gomez J.

7. C. Nuño, P. Pino, M. Ramos. Neumopatías asociadas al SIDA. Acta Médica 2000;9 (1-2):73-89.

8. M. Nieto. Prevalencia de Linfomas no Hodgkin en personas VIH/sida. Universidad Central de Venezuela Facultad de Odontología Postgrado de Cirugía Bucal. Caracas, Mayo 2009.

9. Infecciones respiratorias en el paciente inmunodeprimido. Pérez G.

10. J. Drewes, A. Labra, J. Tenorio. Neumonia por Pneumocystis: Reporte de un caso de evolución fulminante y actualización de su etiología. Revista Chilena de Radiología. Vol. 10 № 4, Año 2004; 172-175.

11. M. Hernández, D. Castillo, F. Bajaña, F Ortega. Pneumocystis Carinii. Presentación de caso clínico y revisión de la bibliografía principal. Vol.

11, núm. 1 (2006).

12. Alanio A, Desoubeaux G, Sarfati C, Hamane S, Bergeron A, Azoulay E, Molina JM Derouin F, Menotti J. Real-time PCR assay-based strategy for differentiation between active Pneumocystis jirovecii pneumonia and colonization in immunocompromised patients. Clin Microbiol Infect 2011; 17: 1531-1537.

13. Miller R. Pneumocystis pneumonia in humans is caused by $P$ jiroveci not $\mathrm{P}$ carinii. Thorax 2004; 59: 83-84.

14. JR Cermeño, I Hernández de Cuesta, F Alcalá, M Áppice. Pneumocystis jiroveci en centros hospitalarios del Estado Bolívar, Venezuela. Rev Biomed 2006; 17:169-174.

15. M Solano, F. Álvarez, S. Grau, C. Segura, A. Aguilar. Neumonía por Pneumocystis jiroveci : Características Clínicas Y factores de Riesgo Asociados a Mortalidad En Una Unidad de Cuidados Intensivos. DOI: 10.1016/j.medin.2013.11.006

16. García M, Ruiz I, Pérez H., Hernández A. Utilización de servicios sanitarios según el sexo en una cohorte de usuarios de drogas por vía parenteral infectados por el virus de la inmunodeficiencia humana. Medicina Clínica 2003;120(13): 489-493.

17. E. Carrillo, A. Villegas. El descubrimiento del VIH en los albores de la epidemia del SIDA. Revista de Investigación Clínica. v.56 n.2 México abr. 2004. Pág. 130-133. 